\title{
ON FIRST ORDER DIFFERENTIAL INCLUSIONS WITH PERIODIC BOUNDARY CONDITIONS
}

\author{
M. BENCHOHRA AND S. K. NTOUYAS
}

Abstract. In this paper a fixed point theorem for condensing maps combined with upper and lower solutions are used to investigate the existence of solutions for first order differential inclusions with periodic boundary conditions.

Mathematics subject classification (2000): 34A60, 34G25.

Key words and phrases: Periodic boundary value problem, convex multivalued map, condensing map, fixed point, truncation map, upper and lower solutions.

\section{REFERENCES}

[1] J. BANAS AND K. GoEBEL, Measures of Noncompactness in Banach Spaces, Marcel Dekker, New York, 1980.

[2] S. Bernfeld And V. Lakshmikantham, An Introduction to Nonlinear Boundary Value Problems, Academic Press, New York, 1974.

[3] A. CABADA, The monotone method for first order problems with linear and nonlinear boundary conditions, Appl. Math. Comp. 63 (1994), 163-186.

[4] S. Carl, S. HeikKILA And M. Kumpulainen, On solvability of first order discontinuous scalar differential equations, Nonlinear Times Digest 21 (1995), 11-27.

[5] C. DE COSTER, The method of lower and upper solutions in boundary value problems, $\mathrm{PhD}$ thesis, Université Catholique de Louvain, 1994.

[6] K. Deimling, Multivalued Differential Equations, De Gruyter, Berlin, 1992.

[7] M. FRIGON, Application de la théorie de la transversalité topologique à des problèmes non linéaires pour des équations différentielles ordinaires, Dissertationes Mathemacae, 296 Warszawa, 1990.

[8] M. FRIGON AND D. O'REGAN, Existence results for some initial and boundary value problems without growth restriction, Proc. Amer. Math. Soc. 1231 (1995), 207-216.

[9] S. HEIKKILA AND A. CABADA, On first order discontinuous differential equations with nonlinear boundary conditions, Nonlinear Word 3 (1996), 487-503.

[10] S. HEIKKILA AND V. LAKSHMIKANTHAM, Monotone Iterative Techniques for Discontinuous Nonlinear Differential Equations, Marcel Dekker, New York, 1994.

[11] N. Halidias And N.S. PAPAgEORgIOU, Second order multivalued boundary value problems, Arch. Math. (Brno) 34 (1998), 267-284.

[12] SH. Hu AND N. PAPAGEORGIOU, Handbook of Multivalued Analysis, Kluwer, Dordrecht, Boston, London, 1997.

[13] G. S. Ladde, V. Lakshmikantham and A. S. Vatsala, Monotone Iterative Techniques for Nonlinear Differential Equations, Pitman, Boston M. A., 1985.

[14] V. LAKSHMIKANTHAM AND S. LEELA, Remarks on first and second order periodic boundary value problems, Nonlinear Anal. 83 (1984), 281-287.

[15] A. LASOTA AND Z. OPIAL, An application of the Kakutani-Ky Fan theorem in the theory of ordinary differential equations, Bull. Acad. Pol. Sci. Ser. Sci. Math. Astronom. Phys. 13 (1965), 781-786.

[16] M. Martelli, A Rothe's type theorem for non compact acyclic-valued maps, Boll. Un. Mat. Ital. 4 (Suppl. Fasc.) (1975), 70-76.

[17] M. N. NKASHAMA, A generalized upper and lower solutions method and multiplicity results for nonlinear first order ordinary differential equations, J. Math. Anal. Appl. 140 (1989), 381-395. 